\title{
WYZWANIA W ZARZĄDZANIU STRATEGICZNYM PRZEDSIĘBIORSTWA NA PODSTAWIE KONCEPCJI ZDOLNOŚCI DYNAMICZNYCH
}

Z a r y s t r e ś c i: W artykule przedstawiono kluczowe zagadnienie stanowiące o wyzwaniach w XXI wieku w zakresie zarządzania strategicznego przedsiębiorstw. Praca ma charakter przeglądowy, którą oparto o krajową i zagraniczną literaturę przedmiotu. Celem głównym jest zwrócenie uwagi na istotne problemy nurtujące zarówno naukowców jak i praktyków gospodarczych. W pracy skupiono się przede wszystkim na pojęciu zdolności dynamicznych w zarządzaniu strategicznym przedsiębiorstw. Przedstawiono główne założenia koncepcji Dynamic Capability View, która cieszy się coraz większym zainteresowaniem wśród naukowców [Barreto, 2010; Vogel i Güttel, 2013; Karna i Richter, 2015]. W zakończeniu zaprezentowano implikacje dla dalszych badań autora.

S ł o w a k 1 u c z o w e: zarządzanie strategiczne; wyzwania w XXI wieku; otoczenie dynamiczne; zdolności dynamiczne, DCV.

Klasyfikacja JEL: L21.

* Adres do korespondencji: Adam Weinert, Uniwersytet Ekonomiczny w Poznaniu, Katedra Zarządzania Strategicznego, al. Niepodległości 10, p. 312A, 61-875 Poznań, email: adam.weinert@ue.poznan.pl 


\section{WSTĘP}

Zarządzanie strategiczne to jedna $\mathrm{z}$ wielu subdyscyplin nauk o zarządzaniu. Jak w każdej dziedzinie naukowej ugruntowały się w niej odpowiednie paradygmaty, podejścia oraz nurty, które są charakterystyczne w jej obszarze. Termin „zarządzanie strategiczne” pojawił się w 1979 roku za sprawą Schendla i Hofera, wypierając wcześniej stosowane pojęcie planowania długookresowego. Od tego czasu powstało wiele opracowań opisujących ewolucję wskazanej dyscypliny badawczej. W literaturze przedmiotu podkreśla się kilka faz rozwoju zarządzania strategicznego: fazę założycielską [m.in. Ansoff 1965], fazę ekonomii branży [m.in. Porter, 1980], fazę ekonomii organizacyjnej [m.in. Eisenhardt 1989] oraz fazę podejścia zasobowego [m.in. Barney, 1991]. Jak wskazuje Czakon [2014], w ramach odrębnych faz widać wyraźnie tworzone wspólnoty zajmujących się nimi badaczy. Należy podkreślić jednak, że zarządzanie strategiczne powstało ze scalenia dwóch dyscyplin naukowych: polityki biznesu (z ang. business policy) oraz ekonomii sektorowej (z ang. industrial organization economics) [Matyjas, 2013, s. 17]. Dynamiczny rozwój zarządzania strategicznego zawdzięcza się silnemu powiązaniu tej dyscypliny naukowej z potrzebami praktyki gospodarczej przedsiębiorstw. Fundamentalnym aspektem zarządzania strategicznego dla badaczy interesujących się tym obszarem nauki jest zmienność otoczenia, w którym funkcjonują przedsiębiorstwa. Mówi się o otoczeniu niepewnym, turbulentnym, czy już nawet dynamicznym, które charakteryzuje się takimi cechami, jak: zmienność granic organizacji, pojawianie się nowych kanałów dystrybucji i kontaktu z klientami, wysoką niepewnością sytuacji decyzyjnych [Eisenhardt i Martin, 2000]. Koźmiński [2014] określa dzisiejszą sytuację przedsiębiorstw w środowisku biznesowym za pomocą metafory jako „czas pokera”, czyli okoliczności uwarunkowań o bardzo wysokim poziomie ryzyka, gdzie podobnie jak w grze karcianej istnieje realna możliwość utraty całej zakładanej stawki.

Współczesne zmiany w otoczeniu przedsiębiorstw skutkują wzrostem zainteresowania problematyką nauk o zarządzaniu. Jednocześnie dziedzina zarządzania strategicznego podlega ciągłym zmianom. Rosnącym zainteresowaniem wśród uczonych cieszy się teoria zdolności dynamicznych, która za sprawą Teece, Pisano i Shuen [1997] została zdefiniowana i przedstawiona na łamach jednego z najbardziej znanych periodyków z zakresu zarządzania strategicznego - Strategic Management Journal. Następnie rozwijana przez kolejnych autorów - Eisenhardt i Martin [2000], Winter 
[2003], Teece [2007], Helfat i inni [2007], Helfat i Winter [2011], Teece [2014].

Celem artykułu jest przedstawienie założeń koncepcji zdolności dynamicznych oraz jej ewolucji na przestrzeni ostatnich lat. W tym celu przeprowadzono krytyczną analizę literatury przedmiotu.

\section{KONCEPCJA DYNAMIC CAPABILITY VIEW - ZAŁOŻENIA}

W dziedzinie zarządzania strategicznego w ostatnich kilkunastu latach dużym zainteresowaniem badaczy cieszy się teoria zdolności dynamicznych (z ang. Dynamic Capability View, w skrócie DCV). Wśród badaczy zadaje się kluczowe pytanie: dlaczego w dynamicznym otoczeniu niektóre firmy potrafią osiągać sukces, a inne nie? Odpowiedź na nie próbuje się uzyskać dzięki wskazanej koncepcji [Arend, Bromiley, 2009]. W ramach założeń tej teorii zastąpiono statyczne podejście (neoliberalne) przez metody szkoły nurtu ewolucyjnego w ekonomii. Jak wskazuje Czakon [2010], zdolności dynamiczne (nazywane również kompetencjami dynamicznymi, $\mathrm{z}$ ang. dynamic capabilities) stanowią próbę integracji dwóch szkół: szkoły uczenia się (z ang. learning view) oraz szkoły zasobowej (z ang. resource based view, w skrócie RBV). Ukierunkowane są one wspólnie na osiągnięcie przez przedsiębiorstwa przewagi konkurencyjnej oraz ponadprzeciętnych wyników biznesowych. Rozwinięcie przez naukowców badań skoncentrowanych na zdolnościach dynamicznych firmy służy eksploracji warunków, w których zasoby z danego okresu mają znaczący wpływ na strategiczną przewagę w kolejnych okresach. Rozpatrywanie kompetencji dynamicznych w czasie sugeruje znaczenie procesu uczenia się w ich kształtowaniu. Wykształcenie jakiejkolwiek kompetencji wymaga jednocześnie w takim ujęciu odpowiedniej powtarzalności i nastawienia na codzienne doskonalenie procesów w przedsiębiorstwie. Koncepcja DCV wiąże się z niedostatkiem teorii zasobowej, która zakłada ujęcie statyczne i nie wskazuje na możliwość zmiany danej wiązki zasobów przedsiębiorstwa. Istotną rolę $\mathrm{w}$ postrzeganiu zdolności dynamicznych odgrywają zmieniające się warunki otoczenia, wpływając na rozwój kategorii dynamicznej [Czakon, 2010]. Zapoczątkowanie teorii zdolności dynamicznej przypisuje się David'owi J. Teece, Gary'emu Pisano i Amy Shuen [1997]. Obecnie koncepcja ta stała się jednym z ważniejszych 
zagadnień zarządzania strategicznego ${ }^{1}$. Napisano już bardzo wiele prac o zdolnościach dynamicznych w ciągu ostatnich dziesięciu lat [Peteraf i inni, 2013]. Koncepcja DCV oznacza nowe kryterium teorii opartych na relacji firma-wyniki [Arend, Bromiley, 2009, s. 75]. Z definicji koncepcji DCV kompetencje dynamiczne oznaczają zdolność firmy do integracji, budowy i rekonfiguracji wewnętrznych i zewnętrznych kompetencji skierowanych do szybko zmieniającego się otoczenia [Teece, Pisano, Shuen, 1997]. W literaturze przedmiotu istnieje już więcej definicji pojęcia zdolności dynamicznych. Wybrane z nich przedstawiono poniżej w tabeli 1 .

Tabela 1. Najważniejsze definicje terminu zdolności dynamicznych w literaturze przedmiotu

\begin{tabular}{|c|c|}
\hline Autorzy & Definicja \\
\hline $\begin{array}{l}\text { Teece D., Pisano } \\
\text { G., Shuen } \\
\text { A. [1997] }\end{array}$ & $\begin{array}{l}\text { Zdolności dynamiczne umożliwiają organizacjom odnowę } \\
\text { kompetencji umożliwiających zarządzanie strategiczne } \\
\text { wewnętrznymi i zewnętrznymi umiejętnościami, rutynami } \\
\text { i zasobami niezbędnymi do utrzymywania wyników w obliczu } \\
\text { zmieniających się warunków otoczenia biznesowego. }\end{array}$ \\
\hline $\begin{array}{l}\text { Eisenhardt K. } \\
\text { M., Martin J. } \\
\text { A. M. [2000] }\end{array}$ & $\begin{array}{l}\text { Zdolności dynamiczne stanowią narzędzie, które może zostać } \\
\text { użyte do manipulowania istniejącymi zasobami przedsiębior- } \\
\text { stwa w celu tworzenia nowych ich konfiguracji. }\end{array}$ \\
\hline Teece [2000] & $\begin{array}{l}\text { Możliwość wykrywania, a następnie szybkiego i sprawnego } \\
\text { wykorzystywania zdolności }\end{array}$ \\
\hline $\begin{array}{l}\text { Zollo M., Winter } \\
\text { S. G. [2002] }\end{array}$ & $\begin{array}{l}\text { Zdolności dynamiczne to wyuczony i stabilny wzorzec/wzor- } \\
\text { ce zbiorowej aktywności, poprzez który organizacja syste- } \\
\text { matycznie generuje i modyfikuje swoje rutyny operacyjne } \\
\text { w poszukiwaniu poprawy efektywności. }\end{array}$ \\
\hline Winter [2003] & $\begin{array}{l}\text { Zdolności które działają, aby przedłużyć, zmienić lub utwo- } \\
\text { rzyć zdolności zwykłe }\end{array}$ \\
\hline $\begin{array}{l}\text { Zahra, Sapienza, } \\
\text { Davidsson [2006] }\end{array}$ & $\begin{array}{l}\text { Możliwości rekonfiguracji zasobów przedsiębiorstwa oraz procedur } \\
\text { w sposób } \\
\text { przewidywał i uznany za właściwy przez jej głównego } \\
\text { decydenta (s) }\end{array}$ \\
\hline
\end{tabular}

1 Praca Teece, Pisano i Shuen [1997] Dynamic Capabilities and Strategic Management została zacytowana już ponad 22 tysiące razy (Google Citation na dzień 03.08.2015 wskazuje 22200 cytowań). Liczba jej cytowań do 2013 roku stale rosła. 
Cd. tab. 1

\begin{tabular}{|l|l|}
\hline \multicolumn{1}{|c|}{ Autorzy } & \multicolumn{1}{c|}{ Definicja } \\
\hline Teece [2007] & $\begin{array}{l}\text { Firmy wymagają zdolności dynamicznych, aby dostosować się do } \\
\text { zmieniających się warunków i ukształtować zajmujące przez nie } \\
\text { ekosystemy. }\end{array}$ \\
\hline $\begin{array}{l}\text { Agarwal, Helfat } \\
\text { [2009] }\end{array}$ & $\begin{array}{l}\text { Zdolności dynamiczne to zdolności organizacji do celowego } \\
\text { tworzenia, rozszerzania lub zmieniania swojej bazy zasobowej. }\end{array}$ \\
\hline Barreto [2010] & $\begin{array}{l}\text { Zdolności dynamiczne jest to potencjał firmy do systematycznego } \\
\text { rozwiązywania problemów, tworzone przez jego skłonność do wy- } \\
\text { korzystywania szanse i wykrywania zagrożenia, aby w odpowiednim } \\
\text { czasie podejmować decyzje i zmieniać jej bazę zasobów }\end{array}$ \\
\hline
\end{tabular}

Źródło: opracowanie własne na podstawie [Barreto, 2010; Wu, 2010; Wójcik-Karpacz, 2012].

W jednym z badań przeprowadzonych przez M. Peteraf i innych [2013] w okresie od 1990 do 2008 roku dostrzega się największe zainteresowanie pracami Teece [1997] oraz Eisenhardt i Martin [2000]. W literaturze przedmiotu widać coraz większe zainteresowanie tematyką koncepcji DCV [Karna, Richter, 2015]. Z drugiej strony, rzadkość do tej pory stanowią prace empiryczne $\mathrm{z}$ tego zakresu [Wu, 2010]. Występuje również coraz więcej prac opartych na konkretnym studium przypadku [np. Czakon, 2008; Danneels, 2011; Aramand, Valliere, 2012; Jones i inni, 2013]. Z kolei Arend i Bromiley [2009, s. 75] wskazują na cztery ważne problemy w zakresie koncepcji DCV: niejasna wartość dodana w stosunku do istniejących pojęć, brak spójnych podstaw teoretycznych, słabe wsparcie empiryczne oraz niejasne implikacje praktyczne.

Barrales-Molina, Martínez-López i Gázquez-Abad [2014] zestawili główne cechy koncepcji DCV (tabela 2), które składają się z czterech elementów: nature, role, microfoundation oraz real DCs. Wybrane zostało one na podstawie syntezy ogólnie przyjętych cech w literaturze przedmiotu.

Zgodnie z definicją przedstawioną przez Barreto [2010], zdolności dynamiczne mogą być widziane jako multiwymiarowy konstrukt składający się z: skłonności do wykrywania szans i zagrożeń, podejmowania w odpowiednim czasie decyzji, podejmowanie decyzji zorientowanych na rynek oraz zmianę bazy zasobów firmy. 
Tabela 2. Cechy koncepcji DCV przyjęte w literaturze przedmiotu

\begin{tabular}{|c|c|}
\hline Cecha & Opis \\
\hline Nature & $\begin{array}{l}\text { - organizacyjne i zamierzone procesy oraz rutyny [Helfat i inni 2007; } \\
\text { Winter 2003; Zollo i Winter 2002] } \\
\text { - procesy powtarzalne (niespontaniczne) [Ambrosini i Bowman } \\
\text { 2009; Zollo i Winter 2002] } \\
\text { - rutyny wyższego rzędu [Collis 1994; Winter 2003] }\end{array}$ \\
\hline Role & $\begin{array}{l}\text { - zmiana zasobów i zdolności [Ambrosini i Bowman 2009; Eisen- } \\
\text { hardt and Martin 2000; Teece i inni 1997; Zahra i inni 2006] } \\
\text { - zmiana rutyn operacyjnych [Zollo i Winter 2002] }\end{array}$ \\
\hline $\begin{array}{l}\text { Microfounda- } \\
\text { tion }\end{array}$ & $\begin{array}{l}\text { - procesy leżące u podstaw: rekonfiguracja, wykorzystania, uczenie } \\
\text { się i twórcza integracja [Teece i inni 1997] } \\
\text { - procesy leżące u podstaw: sensing, seizing, reconfiguring [Teece } \\
\text { 2007] } \\
\text { - bazowe zdolności: innowacyjność, chłonność i zdolność do przy- } \\
\text { stosowania się [Wang i Ahmed 2007] } \\
\text { - nauka mechanizmów do generowania zdolności dynamicznych: } \\
\text { gromadzenie doświadczenia, wiedzy i kodyfikacji wiedzy [Zollo and } \\
\text { Winter 2002] } \\
\text { - powtarzające się praktyki, nauka na błędach z przeszłości i do- } \\
\text { świadczenia [Eisenhardt i Martin 2000; Nielsen 2006] } \\
\text { - próby i błędy, improwizacja i imitacja [Zahra i inni 2006] } \\
\text { - przyczyny niejednoznaczności [Ambrosini i Bowman 2009; Barreto } \\
\text { 2010] }\end{array}$ \\
\hline Real DCs & $\begin{array}{l}\text { - rozwój nowych produktów [Pavlou i El Sawy 2011; Zollo i Winter } \\
\text { 2002] } \\
\text { - współpraca i przejęcia [Karim i Mitchell 2000; Katkalo i inni 2010; } \\
\text { Zollo i Singh 2004] }\end{array}$ \\
\hline
\end{tabular}

Źródło: opracowanie własne na podstawie [Barrales-Molina, Martínez-López i Gázquez-Abad, 2014].

\section{KONCEPCJA ZDOLNOŚCI DYNAMICZNYCH NA TLE TEORII ZASOBOWEJ}

Zgodnie z założeniami podejścia zasobowego (RBV) [Penrose, 1959; Wernerfelt, 1984; Barney, 1986, 1991] przedsiębiorstwo, aby osiągnąć przewagę konkurencyjną, musi posiadać zasoby o potencjale strategicznym. Nieustannie zmieniające się warunki otoczenia sprawiły, że poszukiwane są zasoby gwarantujące większe uodpornienie się na występujące w przy- 
szłości zagrożenia. Nazywane są one meta-kompetencjami [Czakon, 2008] lub zdolnościami „,pierwszego rzędu” (z ang. first order) [Karna, Richter, 2015]. Przedsiębiorstwo, aby rozwijać przewagę konkurencyjną, potrzebuje zarówno zdolności zwykłych (inaczej nazywane operacyjnymi), jak i zdolności dynamicznych [Wójcik-Karpacz, 2012]. Pierwsze z nich pozwalają kontynuować działalność operacyjną. Z kolei zdolności dynamiczne pomagają zmienić istniejące lub stworzyć nowe zdolności [Winter, 2003]. Najważniejsze cechy zdolności dynamicznych przedstawia tabela 3.

Tabela 3. Cechy zdolności dynamicznych

\begin{tabular}{|l|l|}
\hline \multicolumn{2}{|c|}{ Cechy zdolności dynamicznych } \\
\hline \multirow{4}{*}{$\begin{array}{l}\text { Dynamic } \\
\text { capabilities }\end{array}$} & - nieuchwytne \\
\cline { 2 - 2 } & - trudne do zbadania \\
\cline { 2 - 2 } & - sprzeczne \\
\cline { 2 - 2 } & - tautologiczne \\
\hline
\end{tabular}

Źródło: opracowanie własne na podstawie [Karna, Richter, 2015].

Czakon [2010] podkreśla, że grupa zdolności dynamicznych pozostaje otwarta. Zalicza się do nich przykłady obejmujące: kompetencje ułatwiające przeprowadzenie zmian, kompetencje związane z innowacjami, podejmowaniem decyzji strategicznych, rozwój produktów, zdolności zarządzania współpracą, reagowanie na potrzeby rynku, wdrażanie innowacji produktowych oraz umiejętności rozwoju i rekonfiguracji zasobów ludzkich w przedsiębiorstwie (również na poziomie strategicznym) [Czakon, 2008; Karna i Richter, 2015]. Zdaniem B. de Wita i R. Meyera [2007] pojęcie „zdolność” zarezerwowane jest dla połączenia w sobie wielu różnych umiejętności, które z kolei odnoszą się do zadań ograniczonych funkcjonalnie (wąsko zdefiniowanych). Ich zdaniem należy ją utożsamiać z ,możliwościami organizacji w zakresie wykonywania określonych zadań". Helfat i Peteraf [2003] definiują zdolności jako możliwość organizacji do wykonywania skoordynowanych w zestaw zadań w celu osiągnięcia określonego efektu końcowego. Zdolności razem z aktywami zaliczane są do zasobów przedsiębiorstwa [Wade i Hulland, 2004]. 


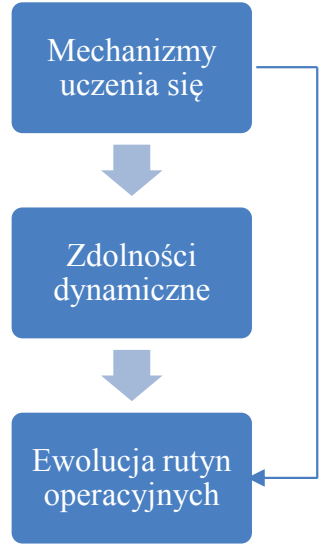

Rysunek 1. Uczenie się, zdolności dynamiczne a rutyny operacyjne Źródło: [Wójcik-Karpacz, 2012, s. 266].

Jak podkreślają Karna i Richter [2015], należy zasadniczo rozróżnić zdolności dynamiczne od zdolności zwykłych (operacyjnych). Zdolności zwykłe (z ang. ordinary capabilities) odzwierciedlają zdolność do wykonywania podstawowych czynności funkcjonalnych przedsiębiorstwa, takich jak logistyka, dystrybucja, czy marketing. W literaturze przedmiotu są nazywane bardzo często również jako rutyny operacyjne lub zdolności „zerowego rzędu" (z ang. zero-order) [Karna, Richter, 2015]. Wielu badaczy doszukuje się powiązań pomiędzy zdolnościami dynamicznymi a rutynami operacyjnymi. Wskazuje się, że zdolności dynamiczne nie tylko rozszerzają lub zmieniają zdolności zwykłe, ale również mogą je nawet tworzyć [Winter, 2003]. Porównanie zdolności dynamicznych z operacyjnymi przedstawiono poniżej w tabeli 4.

Tabela 4. Porównanie zakresu zdolności dynamicznych i rutyn operacyjnych

\begin{tabular}{|l|l|}
\hline \multicolumn{1}{|c|}{ Zwykłych (rutyn) } & \multicolumn{1}{c|}{ dynamicznych } \\
\hline - operacje, procesy, & - B\&R, innowacje, technologia, \\
- produkt, serwis, jakość, & - podejmowanie decyzji strategicznych/ \\
- zasoby/aktywa & /badania rynku \\
- organizacja/struktura & - współpraca, alianse, \\
- relacje z klientami i dostawcami & - zarządzanie wiedzą, \\
& - wartości niematerialne i prawne/reputacja, \\
& - zarządzanie kapitałem ludzkim \\
\hline
\end{tabular}

Źródło: opracowanie własne na podstawie [Karna, Richter, 2015]. 


\section{ZAKOŃCZENIE}

Zainteresowanie prezentowanym zagadnieniem związane jest $\mathrm{z}$ dużą dynamiką i złożonością zmian w zarządzaniu współczesnym przedsiębiorstwem. W treści artykułu skoncentrowano się na koncepcji zarządzania przedsiębiorstwem z wykorzystaniem roli zdolności dynamicznych w zakresie zarządzania strategicznego. Na tle wielu prac teoretycznych poświęconych zagadnieniu koncepcji DCV dostrzega się coraz więcej przedstawianych praktycznych przykładów z biznesu. Kategoria kompetencji dynamicznych jest istotna dla dalszych badań z zakresu zarządzania strategicznego [Czakon, 2008]. Pozostaje jednak wciąż duża luka w zakresie operacjonalizacji zdolności dynamicznych w przedsiębiorstwie i ich wpływu na rozwój przedsiębiorstwa. Należy szukać większego zrozumienia w składowych zdolności dynamicznych tak, aby uzyskać precyzyjne narzędzia dla ich możliwie dokładnego pomiaru [Wójcik-Karpacz, 2012].

\section{LITERATURA}

Agarwal R., Helfat C. E. (2009), Strategic renewal of organizations, Organization Science, Vol. 20, No. 2.

Aramand M., Valliere D. (2012), Dynamic capabilities in entrepreneurial firms: a case study approach, Journal of International Entrepreneurship, Vol. 10, pp. 142-157.

Arend R. J., Bromiley P. (2009), Assessing the dynamic capabilities view: spare change, everyone?, Strategic Organization, Vol. 7(1), pp. 75-90.

Barney J. B. (1991), Firm resources and sustained competitive advantage, Journal of Management, Vol. 17, No. 1, p. 102.

Barrales-Molina V., Martínez-López F., Gázquez-Abad J. C. (2014), Dynamic Marketing Capabilities: Toward an Integrative Framework, International Journal of Management Reviews, Vol. 16, pp. 397-416.

Barreto I. (2010), Dynamic capabilities: a review of past research and an agenda for the future, Journal of Management, Vol. 36, pp. 256-280.

Czakon W. (2008), Kompetencje dynamiczne w badaniach zarzadzania strategicznego, [w:] Krupski R. (red.) Zarzadzanie strategiczne - podstawowe problemy, Prace Naukowe Wałbrzyskiej Wyższej Szkoły Zarządzania i Przedsiębiorczości, Wałbrzych.

Czakon W. (2010), Dynamiczne podejście do zarządzania, Acta Universitatis Lodziensis Folia Oeconomica, Vol. 234. 
Czakon W. (2014), Szkoty a mody w zarzadzaniu strategicznym, Prace Naukowe WWSZiP, nr 27 (2), Zarządzanie strategiczne - Rozwój koncepcji i metod, Wałbrzych.

Danneels E. (2011), Trying to become a different type of company: dynamic capability at Smith Corona, Strategic Management Journal, Vol. 32, pp. 1-31.

De Wit B., Meyer R. (2007), Synteza strategii, PWE, Warszawa.

Eisenhardt K. M., Martin J. A. (2000), Dynamic capabilities: what are they?, Strategic Management Journal, Vol. 21 (10-11).

Helfat C. E., Finkelstein S., Mitchell W., Peteraf M., Singh H., Teece D., Winter S. G. (2007), Dynamic capabilities: Understanding strategic change in organizations, Wiley-Blackwell: Malden, MA.

Helfat C. E., Winter S. G. (2011), Untangling dynamic and operational capabilities: Strategy for the (n)ever-changing world, Strategic Management Journal, Vol. 32(11), pp. 1243-1250.

Jones O., Ghobadian A., O’Reagan N., Antcliff V. (2013), Dynamic capabilities in a sixth-generation family firm: entrepreneurship and the Bibby Line, $\mathrm{Bu}-$ siness History, Vol. 55, pp. 910-933.

Karna A., Richter A., Riesenkampff E. (2015), Revisiting the role of the environment in the capabilities-financial performance relationship: A meta-analysis, Strategic Management Journal, May, 2015.

Koźmiński A. K. (2014), Czas pokera, Wolters Kluwer, Warszawa.

Matyjas Z. (2013), Wzorce konkurowania przedsiębiorstw w sektorach. Podejście dynamiczne, Wydawnictwo Uniwersytetu Łódzkiego, Łódź.

Peteraf M., Stefano G. D., Verona G. (2013), The elephant in the room of dynamic capabilities: bringing two diverging conversations together, Strategic Management Journal, Vol. 34, pp. 1389-1410.

Teece D. J., Pisano G., Shuen A. (1997), Dynamic Capabilities and Strategic Management, Strategic Management Journal, Vol. 18, Nr 7, pp. 509-534.

Teece D. J. (2007), Explicating dynamic capabilities: The nature and microfoundations of (sustainable) enterprise performance, Strategic Management Journal, Vol. 28(13), pp. 1319-1350.

Teece D. J. (2014). The foundations of enterprise performance: Dynamic and ordinary capabilities in an (economic) theory of firms, Academy of Management Perspectives, Vol. 24(4), pp. 328-352.

Vogel R., Güttel W. H. (2013), The dynamic capabilities view in strategic management: a bibliometric review, International Journal of Management Reviews, Vol. 15, pp. 426-446. 
Wade M., Hulland J. (2004), Review: The resource-based view and information systems research: Review, extension and suggestions for future research, MIS Quarterly, Vol. 28(1), pp. 107-142.

Winter S. G. (2003), Understanding Dynamic Capabilities, Strategic Management Journal, Vol. 24(10): pp. 991-995.

Wit B., Meyer R. (2007), Synteza strategii, PWE, Warszawa.

Wójcik-Karpacz A. (2012), Zdolności dynamiczne jako przedmiot eksploracji naukowej zarzadzania strategicznego, [w:] Krupski R. (red.) Zarzadzanie strategiczne Quo Vadis?, Prace Naukowe WWSZiP, nr 22(2).

Wu Lei-Yu (2010), Applicability of the resource-based and dynamic-capability views under environmental volatility, Journal of Business Research, Vol. 63, pp. 27-31.

Zollo M., Winter S. G. (2002), Deliberate learning and the evolution of dynamic capabilities, Organization Science, Vol. 13.

\title{
THE CHALLENGES IN STRATEGIC MANAGEMENT ENTERPRISES ON THE BASIS OF THE CONCEPT OF DYNAMIC CAPABILITIES
}

\begin{abstract}
The article presents the key issue of forming the challenges of the twenty-first century in the strategic management of enterprises. Work is a review, which was based on domestic and foreign literature on the issue. The main goal is to draw attention to important problems facing both academics and business practitioners. The study focuses primarily on the concept of dynamic capability in strategic management. The article presents the main assumptions of the concept of Dynamic Capability View, which is becoming increasingly popular among scientists [Barreto 2010, Vogel and Güttel to 2013, Karna and Richter, 2015]. At the end of the implications presented for further study.
\end{abstract}

Keywords: strategic management; challenges in the twenty-first century; dynamic environment; dynamic capabilities; DCV. 